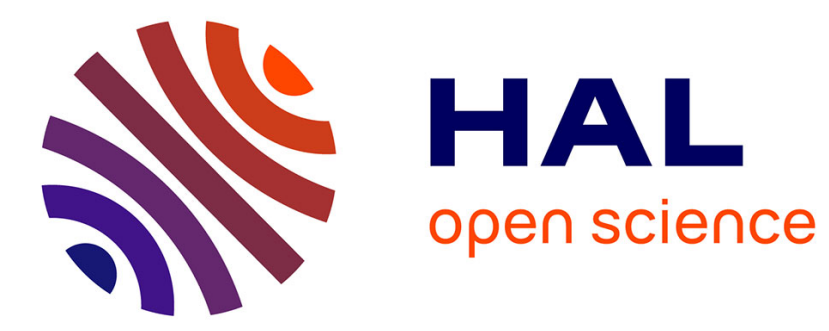

\title{
First-principles study of sulfur multi-absorption in nickel and its segregation to the $\mathrm{Ni}(100)$ and $\mathrm{Ni}(111)$ surfaces
}

Dmytro Kandaskalov, Daniel Monceau, Claude Mijoule, Damien Connétable

\section{To cite this version:}

Dmytro Kandaskalov, Daniel Monceau, Claude Mijoule, Damien Connétable. First-principles study of sulfur multi-absorption in nickel and its segregation to the $\mathrm{Ni}(100)$ and $\mathrm{Ni}(111)$ surfaces. Surface Science: A Journal Devoted to the Physics and Chemistry of Interfaces, 2013, vol. 617, pp. 15-21. 10.1016/j.susc.2013.06.019 . hal-01170366

\section{HAL Id: hal-01170366 https://hal.science/hal-01170366}

Submitted on 1 Jul 2015

HAL is a multi-disciplinary open access archive for the deposit and dissemination of scientific research documents, whether they are published or not. The documents may come from teaching and research institutions in France or abroad, or from public or private research centers.
L'archive ouverte pluridisciplinaire $\mathbf{H A L}$, est destinée au dépôt et à la diffusion de documents scientifiques de niveau recherche, publiés ou non, émanant des établissements d'enseignement et de recherche français ou étrangers, des laboratoires publics ou privés. 


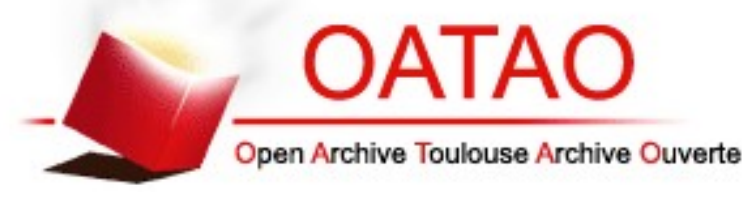

\section{Open Archive TOULOUSE Archive Ouverte (OATAO)}

OATAO is an open access repository that collects the work of Toulouse researchers and makes it freely available over the web where possible.

This is an author-deposited version published in : http://oatao.univ-toulouse.fr/ Eprints ID : 14062

To link to this article : DOI:10.1016/j.susc.2013.06.019

URL : $\underline{\text { http://dx.doi.org/10.1016/j.susc.2013.06.019 }}$

To cite this version : Kandaskalov, Dmytro and Monceau, Daniel and Mijoule, Claude and Connétable, Damien First-principles study of sulfur multi-absorption in nickel and its segregation to the Ni(100) and Ni(111) surfaces. (2013) Surface Science, vol. 617. pp. 15-21. ISSN 0039-6028

Any correspondance concerning this service should be sent to the repository administrator: staff-oatao@listes-diff.inp-toulouse.fr 


\title{
First-principles study of sulfur multi-absorption in nickel and its segregation to the $\mathrm{Ni}(100)$ and $\mathrm{Ni}(111)$ surfaces
}

\author{
Dmytro Kandaskalov, Daniel Monceau, Claude Mijoule, Damien Connétable * \\ CIRIMAT, UMR 5085, CNRS-INP-UPS École Nationale d'Ingénieurs en Arts Chimiques et Technologiques (ENSIACET) 4, allée Émile Monso, BP 44362 , F-31030 Toulouse Cedex 4, France
}

\begin{abstract}
A B S T R A C T
It is of both experimental and fundamental interest to understand the sulfur (S) properties of metallic alloys. Therefore, in this work, we present the physical and chemical properties of sulfur in Ni-fcc solid solution and its chemisorption on the $\mathrm{Ni}(100)$ and $\mathrm{Ni}(111)$ surfaces using the density functional theory. It is shown that the substitutional site is more stable than the interstitial sites because of a significant "vacancy-sulfur" interaction and steric effects. The migration mechanism of $\mathrm{S}$ atoms in a solid solution is presented in detail, and our results are compared to the experimental data. We also discuss the interactions between sulfur and the vacancies. Adsorption of $\mathrm{S}$ on the $\mathrm{Ni}(100)$ and $\mathrm{Ni}(111)$ surfaces arises preferably on the most coordinated sites. A large segregation energy is calculated for the $\mathrm{Ni}(100)$ and $\mathrm{Ni}(111)$ surfaces.
\end{abstract}

\section{Introduction}

Sulfur (S) segregation in pure metals and alloys had been observed and studied for many years. Sulfur segregation at the nickel surface is a model system to study the surface segregation phenomena [1]. $S$ segregates at both free surfaces and internal interfaces such as cavities, grain boundaries, inter-phases [2] and metal/oxide interfaces. These segregations have large detrimental consequences. At the surface, $S$ degrades the catalytic activity of the metals [3]. Grain boundary sulfur segregation leads to the embrittlement of nickel and steels [1-3]. More recently, considerable attention has been paid to sulfur segregation at the interface between $\mathrm{Ni}-\mathrm{Al}, \mathrm{Ni}-\mathrm{Cr}-\mathrm{Al}, \mathrm{Fe}-\mathrm{Al}, \mathrm{Fe}-\mathrm{Cr}-\mathrm{Al}$ structural alloys and intermetallics and their alumina protective oxide scale [4,5]. $\mathrm{H}_{2}$ annealing of alloys [6], which are doped with reactive elements (e.g. Y, Hf...) [4] and Pt [7] has been shown to reduce the detrimental effect of $\mathrm{S}$ on the adherence of the oxide scale and to improve the durability of the high temperature alloys. Consequently, the understanding of S segregation, desegregation, diffusion and gettering in metallic alloys is of both experimental and fundamental interest. Experimental data are available concerning $\mathrm{S}$ segregation at $\mathrm{Ni}$ surface [1], but the precise location and the diffusion mechanism of $\mathrm{S}$ in metal are not clearly understood to date. This understanding is necessary because the $\mathrm{S}$ segregation at a free surface depends on the energy of the $\mathrm{S}$ atom in the gas phase and in the bulk $\mathrm{Ni}[1,8]$ and because the $S$ atom can be exchanged between the bulk and the surface by diffusion. In oxidized systems and grain boundary systems, the bulk state of $S$ is used as the reference to study the segregations. Finally the diffusion of

\footnotetext{
* Corresponding author. Tel.: + 33534323410.

E-mail address: damien.connetable@ensiacet.fr (D. Connétable).
}

$S$ determines the segregation kinetics, and the desulfurization kinetics of the alloys in an H2-containing atmosphere [6]. To clarify various experimental and theoretical data concerning the sulfur contamination of metals and alloys, we present a basic interaction of S with nickel. Our calculations concern the interstitial and substitution dissolution of $S$ in the bulk, its adsorption and its segregation process on the $\mathrm{Ni}(100)$ and $\mathrm{Ni}(111)$ surfaces. Furthermore, we determine the ability of a mono-vacancy and a divacancy (substitution site) to trap several sulfur atoms. The energetic properties of the $S$ atom in the bulk and on the surfaces allow us to evaluate the segregation energy.

\section{Computational details}

The calculations were performed within the density functional theory (DFT) formalism and the pseudo-potential approximation, which were conducted using the Vienna ab initio simulation program (VASP) [9]. We used the Projected Augmented Waves (PAW) pseudopotentials [10] (10 and 6 electrons for $\mathrm{Ni}$ and $\mathrm{S}$ atoms, respectively) and the spin-polarized Perdew-Wang generalized gradient approximation (SGGA) [11] for the exchange and correlation functionals. Regarding the computational parameters, the plane-wave energy cut-off is maintained at 14.7 Ryd ( $400 \mathrm{eV}$ ) for all calculations. In addition, a $4 \times 4 \times 4$ Monkhorst-Pack [12] mesh is used to sample the Brillouin zone in the reciprocal space for all calculations related to the absorption of $S$ atom in the nickel bulk. Lattice relaxations were considered and all ions and defects were allowed to relax. The supercells containing $108 \mathrm{Ni}$ atoms $(3 \times 3 \times 3$ cubic supercell, with $\mathrm{a}_{o}=3.52 \AA$ ) are used to study the $\mathrm{S}$ absorption in the bulk (migration and solubility). 
To calculate the energy of the isolated S atom, the polarization and the broken symmetry contributions were introduced. The DFT ground state energy of $\mathrm{S}$ atom and the dissociation energy of $\mathrm{S}_{2}$ in the gas phase were approximately $-0.845 \mathrm{eV}$ and $2.64 \mathrm{eV} /$ atom, respectively, which were larger than the experimental data (2.2 eV [13]). To validate the pseudo-potential, we also compute the frequency of the diatomic system $(\mathrm{d}(\mathrm{S}-\mathrm{S})=1.90 \AA$, whereas that of the experimental data is $1.88 \AA$ ). We obtain $683 \mathrm{~cm}^{-1}$, which agrees with the experimental value $\left(715 \mathrm{~cm}^{-1}\right)$ [14].

To study the segregation and the adsorption on the surfaces mentioned in Section 4, we used a slab system. The $\mathrm{Ni}(100)$ and $\mathrm{Ni}(111)$ surfaces were built using the symmetric supercell approach. The crystal surfaces were represented by optimal slabs which are composed by 12 and 13 atomic layers for the $\mathrm{Ni}(111)$ and the $\mathrm{Ni}(100)$ surface, respectively (as illustrated Fig. 1 ). The $2 \times 2$ supercells in the $x-y$ plane were used. These choices correspond to a sulfur coverage of 0.125 , which is low enough to neglect the sulfur-sulfur interaction on the surfaces.

For each surface, a symmetric slab was used and the calculations were performed with $9 \times 9 \times 1 \mathrm{k}$-meshes. Three criteria of convergence were considered to choose an optimal number of layers for each surface: the surface energy, the inter-layer distances and the forces. To avoid an artificial dipole moment on the surface because of the foreign additional atom, we introduced one atom of sulfur to each side of the slab. Furthermore, the distance between the slabs generated by the periodicity was adapted to avoid the artificial inter-surface interactions: it corresponds to 7 empty layers for the $\mathrm{Ni}(111)$ surface $(\mathrm{d}=14.2 \AA)$ and 8 empty layers for the $\mathrm{Ni}(100)$ surface $(\mathrm{d}=16.3 \AA$ ), as shown in Fig. 2 .

\section{Sulfur in solid solution}

\subsection{Where are the $S$ atoms located?}

First, we study the solubility of the $S$ atoms in nickel. The impurities can be located in three sites: the substitution site (i.e., instead of a solute atom) and the two insertion sites, which are the octahedral site $(\mathrm{O})$ and the tetrahedral site $(\mathrm{T})$, as illustrated in Fig. 3.

To identify in which site(s) the $S$ atoms prefer to be located, we used two energies according to the site: the solution energy $\left(E^{\text {sol }}\right)$

\section{side view}
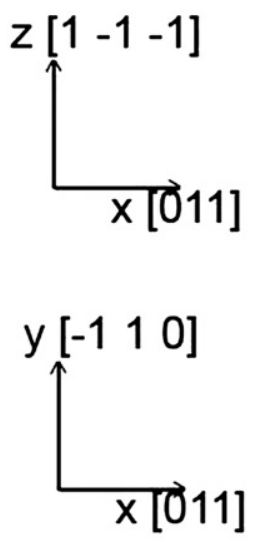

top view
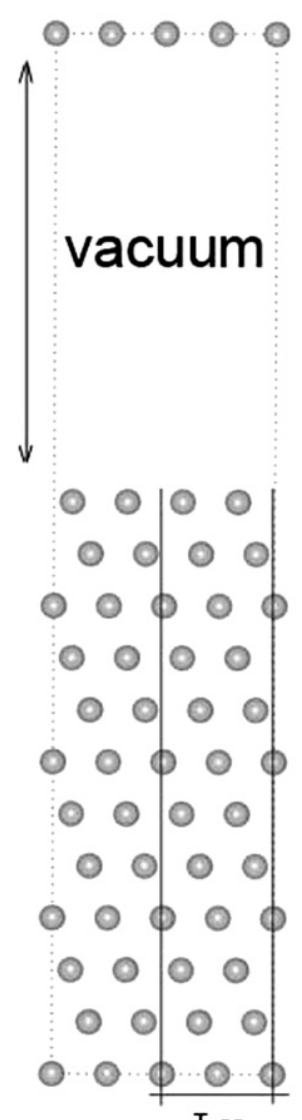

Lx

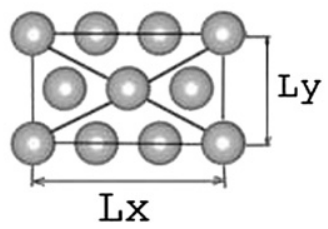

$\mathrm{Ni}(111)$

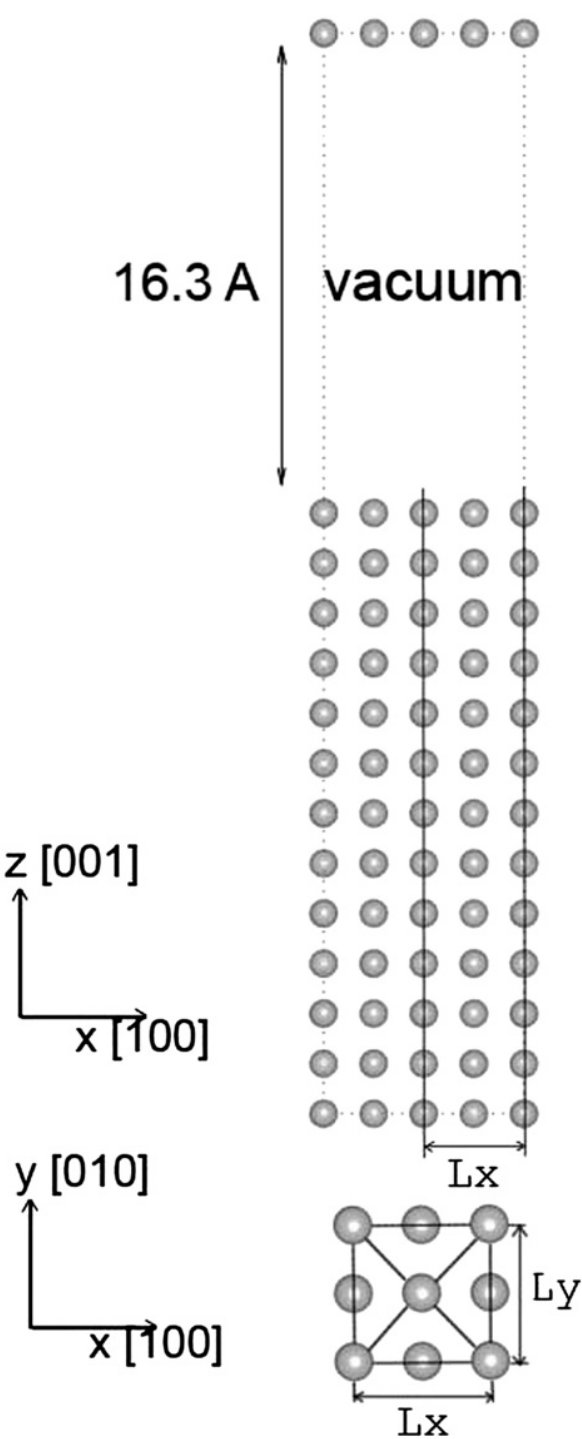

$\mathrm{Ni}(100)$

Fig. 1. Schematic representation of both surfaces: $\mathrm{Ni}(111)$ and $\mathrm{Ni}(100)$. 

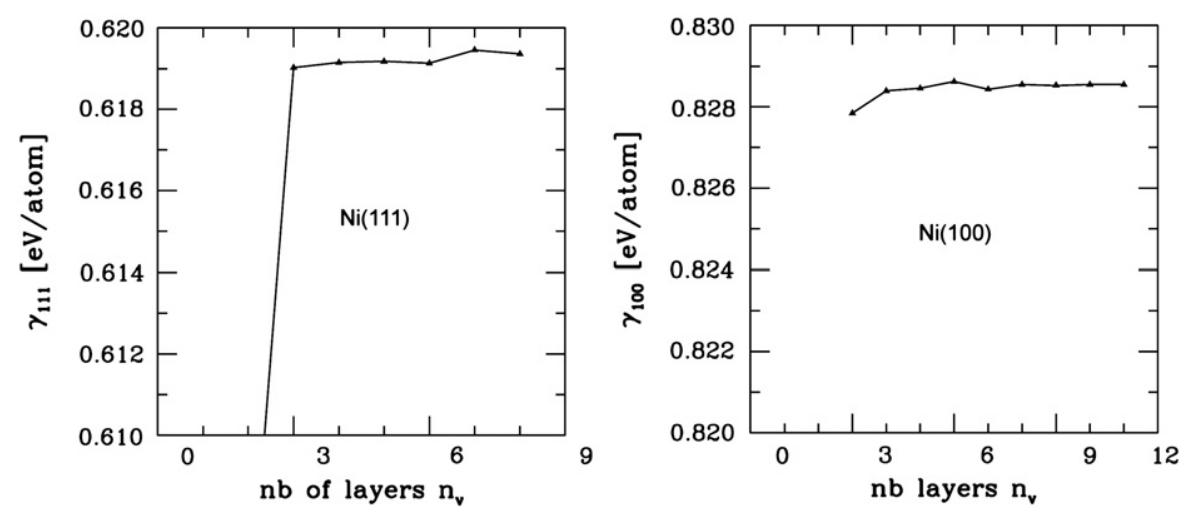

Fig. 2. Evolution of the surface energy versus the size of the empty layers $\left(\mathrm{n}_{v}\right): \mathrm{Ni}(111)$ and $\mathrm{Ni}(100)$.

and the insertion energy ( $\left.E^{\text {ins }}\right)$. The $E^{\text {sol }}$ value of an impurity in an insertion site in fcc-Ni is given by

$\mathrm{E}^{\mathrm{sol}}=\mathrm{E}_{o}[n \cdot \mathrm{Ni}+\mathrm{S}]-\mathrm{E}_{o}[n \cdot \mathrm{Ni}]-\frac{1}{2} \mathrm{E}_{o}\left[\mathrm{~S}_{2}\right]$

where the reference state is the $S_{2}$ molecule $\left(E_{o}\left[S_{2}\right]\right)$ and the insertion energy $E^{\text {ins }}$, in the $(\mathrm{T})$ and $(\mathrm{O})$ sites is expressed as:

$\mathrm{E}^{\mathrm{ins}}=\mathrm{E}_{o}[n \cdot \mathrm{Ni}+\mathrm{S}]-\mathrm{E}_{o}[n \cdot \mathrm{Ni}]-\mathrm{E}_{o}\left[\mathrm{~S}_{\text {atom }}\right]$

where $\mathrm{E}_{o}\left[\mathrm{~S}_{\text {atom }}\right]$ is the atomic energy. $\mathrm{E}_{o}[n \cdot \mathrm{Ni}+\mathrm{S}]$ is associated with the total energy of the supercell (bulk) that has $n$ atoms of nickel and one $\mathrm{S}$ atom, which is inserted either in the interstitial octahedral (O) site or the tetrahedral $(T)$ site. $E_{o}[n \cdot N i]$ is the total energy of the supercell without sulfur. For the substitutional sites, we have equivalent equations for the solution and the insertion energies (not to forget that we removed one Ni atom):

$\mathrm{E}^{\text {ins }}=\mathrm{E}_{o}[(n-1) \cdot \mathrm{Ni}+\mathrm{S}]-\frac{n-1}{n} \cdot \mathrm{E}_{o}[n \cdot \mathrm{Ni}]-\mathrm{E}_{o}\left[\mathrm{~S}_{\text {atom }}\right]$

and for solubility energy $\mathrm{E}^{\mathrm{sol}}$ :

$\mathrm{E}^{\mathrm{sol}}=\mathrm{E}_{o}[(n-1) \cdot \mathrm{Ni}+\mathrm{S}]-\frac{n-1}{n} \cdot \mathrm{E}_{o}[n \cdot \mathrm{Ni}]-\frac{1}{2} \mathrm{E}_{o}\left[\mathrm{~S}_{2}\right]$.

Thus, $E^{\text {sol }}-E^{\text {ins }}=E_{\text {diss }}\left[S_{2}\right]$, where $E_{\text {diss }}\left[S_{2}\right]$ is the dissociation energy of $\mathrm{S}_{2}$.

The values were calculated using the energies ( $E^{\text {ins }}$ and $\left.E^{\text {sol }}\right)$, where the reference states were computed using DFT. The results are listed in Table 1.

When the interstitial and substitutional sites for the $\mathrm{S}$ atoms in $\mathrm{Ni}$-fcc are compared with each other, the results indicate that $S$ atoms prefer the substituted sites, which agree with the experimental assumptions [1]. The difference in energy between the $(0)$ and $(S)$ sites
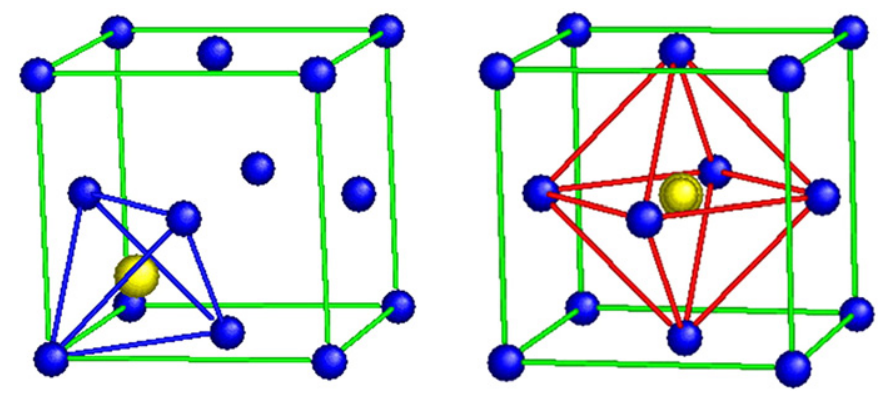

Fig. 3. Insertion sites in the fcc structures: the tetrahedral site (left), and the octahedral site (right).
$\left(\Delta=\mathrm{E}_{\text {octa }}^{\text {sol }}-\mathrm{E}_{\text {sub }}^{\text {sol }}\right)$ is large: $\Delta \simeq 1.30 \mathrm{eV}$. In the first-order approximation, compared to the substitutional site, the fraction of $S$ atoms in the octahedral, which is expressed by $\exp \left(-\Delta / k_{B} T\right)$, is negligible even at high temperature $\left(10^{-15}\right.$ at $\left.1000 \mathrm{~K}\right)$.

Our insertion energy value is in excellent agreement with the experimental values ( $-2.54 \mathrm{eV}[15])$. Regarding the solution energy, we notice that our simulations also agree with the experimental data $(-0.57 /-0.67 \mathrm{eV}[15,24])$. The calculated solution energies for the insertion sites are positive (approximately 1.06 and $2.24 \mathrm{eV}$ ), which shows that they are not stable compared to the $S_{2}$ molecule.

We evaluated the vibrational free energy $\left(\mathrm{F}_{\mathrm{ZPE}}\right.$, the zero point energy) at $0 \mathrm{~K}$. Within the quasi-harmonic approximation, $\mathrm{F}_{\mathrm{ZPE}}$ (calculated with a $2 \times 2 \times 2$ supercell at the $\Gamma$ point) is given by:

$\mathrm{F}_{Z P E}=\mathrm{E}_{v i b}[(n-1) \cdot \mathrm{Ni}+\mathrm{S}]-\frac{n-1}{n} \cdot \mathrm{E}_{v i b}[n \cdot \mathrm{Ni}]$

where $\mathrm{E}_{v i b}[X]=\sum \hbar \omega_{q=\Gamma, \nu}[X] / 2$ is the vibrational energy calculated with and without sulfur. The calculated value of $\mathrm{F}_{\mathrm{ZPE}}$ is small, which is approximately $-13 \mathrm{meV}$. If we include the contribution of $S_{2}$, which is $-21 \mathrm{meV}\left(=-683 / 4 \mathrm{~cm}^{-1}\right.$ as provided above), the ZPE is equal to approximately $-34 \mathrm{meV}$. This value is too low to significantly modify the formation enthalpy of the $\mathrm{S}$ atom in nickel.

If one $\mathrm{S}$ atom in substitution is moved into an octahedral site and creates a new vacancy, i.e.,

"bulk" $+S_{\text {sub }} \rightleftharpoons$ "bulk +1 vacancy" $+\mathrm{S}_{\text {octa }} \quad \mathrm{E}_{\text {form }}$

we find a large energy, $\mathrm{E}_{\text {form }}=-2.67 \mathrm{eV}$, which implies that the $S$ atoms prefer to stay in substitution.

In Table 1, we also provide one additional parameter: the atomic distances around the $\mathrm{S}$ atoms. The comparison between the unrelaxed and the relaxed $\mathrm{S}-\mathrm{Ni}$ and $\mathrm{Ni}-\mathrm{Ni}$ bond lengths around sulfur shows that the interstitial insertion leads to a strong wrapping of the crystal

Table 1

Insertion and solubility energies ( $\mathrm{E}^{\text {ins }}$ and $\mathrm{E}^{\mathrm{sol}}$, measured in $\mathrm{eV}$ ) and the relaxed and unrelaxed distances $\left(d_{\mathrm{Ni}-\mathrm{s}}\right.$ and $d_{\mathrm{Ni}-\mathrm{Ni}}$, measured in $\AA$ ) for each configuration $(\mathrm{CI}=$ initial configuration, $\mathrm{CR}=$ relaxed configuration $)$.

\begin{tabular}{|c|c|c|c|c|c|}
\hline & & \multicolumn{3}{|l|}{ Theo. } & \multirow{2}{*}{$\frac{\text { Exp. }}{[15,24]}$} \\
\hline & & (0) & $(\mathrm{T})$ & $(\mathrm{S})$ & \\
\hline $\mathrm{E}^{\text {ins }}$ & ref. S & -1.581 & -0.403 & -2.887 & -2.54 \\
\hline $\mathrm{E}^{\mathrm{sol}}$ & ref. $\mathrm{S}_{2}$ & 1.055 & 2.233 & -0.252 & $-0.57 /-0.67$ \\
\hline \multirow[t]{2}{*}{$d_{\mathrm{Ni}-\mathrm{s}}$} & $\mathrm{Cl}$ & 1.76 & 1.52 & 2.49 & \\
\hline & $\mathrm{CR}$ & 2.03 & 1.97 & 2.49 & \\
\hline \multirow[t]{2}{*}{$d_{\mathrm{Ni}}-\mathrm{Ni}$} & $\mathrm{CI}$ & 2.49 & 2.49 & 2.49 & \\
\hline & CR & 2.87 & 3.22 & 2.49 & \\
\hline
\end{tabular}


around the $\mathrm{S}$ atom. This wrapping causes a significant increase of the $\mathrm{Ni}-\mathrm{Ni}$ distances between the first nearest neighbors around the sulfur and a large increase of the $\mathrm{S}-\mathrm{Ni}$ distance when the crystal relaxes. For instance, this effect is much smaller for oxygen [16], which allows us to attribute this strong deformation to the steric effects.

\subsection{How do $S$ atoms diffuse?}

When the $\mathrm{S}$ atoms are located in the substituted sites, they diffuse into the crystalline solids via a vacancy mechanism described by the so-called "five-frequency model", which was proposed by Lidiard [17]. Thus, the macroscopic diffusion coefficient of the substituted sites can be written in terms of microscopic parameters, i.e., the lattice parameter $\left(\mathrm{a}_{0}\right)$, the jump frequency of the $\mathrm{S}$ atom into the first nearest neighboring vacancy $\left(\Gamma_{2}\right)$, the vacancy concentration $\left(C_{1 v}\right)$, the Gibbs free energy of solute-vacancy interaction $\left(G^{B}\right)$ and a correlation factor $\mathrm{f}_{2}$, which depends on the structure (here, the structure is fcc) [18]:

$\mathrm{D}=f_{2} p a_{0}^{2} \Gamma_{2}$

where $p=C_{1 v} \exp \left(G^{B} / k_{B} T\right)$ denotes the probability that a vacancy occupies a nearest-neighboring site of the solute. In the main cases, we neglect $G^{B}$, and identify $p$ with $C_{1 v}$. However, as we will observe below, in the case of sulfur, this term cannot be neglected. The vacancy concentration is provided by:

$C_{1 v}=\exp \left[\mathrm{S}_{\mathrm{vib}}^{f} / k_{B}\right] \exp \left[-\mathrm{H}_{1 v}^{f} / k_{B} T\right]$

where $\mathrm{H}_{1 v}^{f}$ is the formation enthalpy of a monovacancy (which is equal to approximately $1.41 \mathrm{eV}[19,20])$, and $\mathrm{S}_{1 v}^{f}$ is the formation entropy (which is neglected in the following). The correlation factor, $\mathrm{f}_{2} \simeq \Gamma_{1} /\left(\Gamma_{2}+\Gamma_{1}\right)$, was derived by Manning [21] when the dissociation jumps are strongly unlikely for a tightly bound solute-vacancy pair, $\Gamma_{1,2} \gg \Gamma_{3}$, i.e., $\mathrm{E}_{3}^{m} \gg \mathrm{E}_{1,2}^{m} . \Gamma_{3}$ characterizes the dissociation rate of the solute-vacancy pair. In this case $E_{3}^{m}$ is at least equivalent to the migration energy of the vacancy (we found approximately $1.1 \mathrm{eV}$ using an NEB approach, which is equivalent to the migration of the monovacancy). $\Gamma_{2}$ is the solute-vacancy exchange rate, and $\Gamma_{1}$ is the rotation rate of the solute-vacancy pair, i.e., the "migration" of the vacancy in first nearest neighboring position of the solute through other 1NN configuration.

Moreover, if the vacancy-solute exchanges occur much faster than the vacancy-solvent exchanges, i.e., if $\Gamma_{2} \gg \Gamma_{1}$, the correlation factor tends to zero, and the motion of the solute atom is highly correlated. The solute atom "rattle" frequently back and forth between two adjacent lattice sites.

In agreement with the transition state theory [22], $\Gamma_{i}$ can be written in terms of the migration enthalpy $\left(\mathrm{H}_{i}^{m}\right)$, and the effective frequency $\nu_{i}^{*}$ : $\Gamma_{i}=\nu_{i}^{*} \exp \left(-\mathrm{H}_{i}^{m} / k_{B} T\right)$ where $\nu_{i}^{*}$ is provided by:

$\nu_{i}^{*}=\prod_{j=1}^{3 N-3} \omega_{j}^{I S} / \prod_{j=1}^{3 N-4} \omega_{j}^{T S}$

where $\omega_{j}$ are the eigen-frequencies of the system in the initial state (labeled IS) and the migration state (TS).

First, we compute the vacancy-sulfur exchange migration energy $\Gamma_{2}: v_{2}^{*}$ and $\mathrm{H}_{2}^{m}=\mathrm{H}^{m}[V S]$. In this specific case, because the initial and the final configurations are equivalent and because the migration path is short and direct (the S atom must jump only once), the transition state is located in the middle of the migration path, as illustrated in Fig. 4. We computed the initial state energy, the saddle point and the migration energy.

The migration energy between an $\mathrm{S}$ atom and a vacancy $\left(\mathrm{H}_{2}^{m}\right)$, in the first neighboring position, is low $(+0.13 \mathrm{eV})$, compared to other

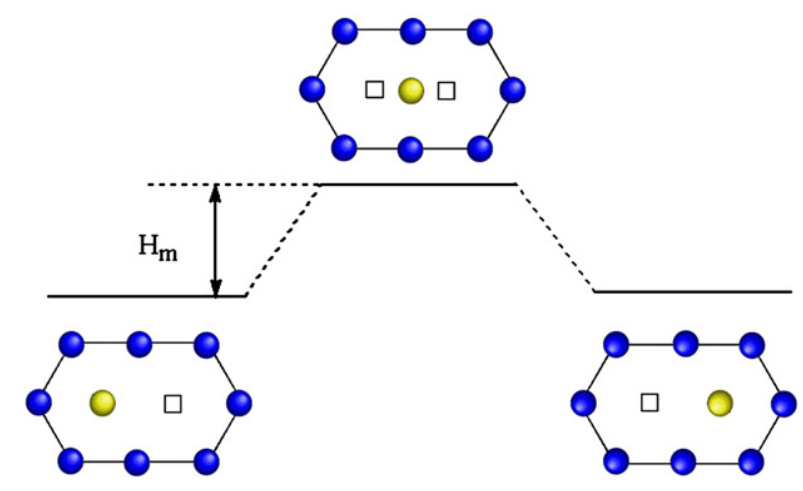

Fig. 4. Representation of the migration path of an $\mathrm{S}$ atom towards its first neighboring vacancy.

impurities in $\mathrm{Ni}-\mathrm{fcc}$ (0.66 eV for $\mathrm{Nb}$ [19], $1.0 \mathrm{eV}$ for the vacancy and $1.07 \mathrm{eV}$ for Mo [23]). Thus $\Gamma_{2} \gg \Gamma_{j}$ (where $\mathrm{j}=1,3$ ) is verified.

We have also computed the effective frequency from the frequencies of the transition (TS) and the initial states (IS). In the first-order approximation, we considered that only the frequencies of the $\mathrm{S}$ atoms are changed between (TS) and (IS), thus:

$\nu_{2}^{*}=\frac{\prod_{i=1}^{3 N-3} \omega_{i}^{\mathrm{IS}}}{\prod_{i=1}^{3 N-4} \omega_{i}^{\mathrm{TS}}} \simeq \frac{\prod_{i=1}^{3} \omega_{i}^{\mathrm{IS}}[\mathrm{S}]}{\prod_{i=1}^{2} \omega_{i}^{\mathrm{TS}}[\mathrm{S}]}$

We obtained $\omega_{v}^{\mathrm{IS}}=165,124$, and $60 \mathrm{~cm}^{-1}$, and $\omega_{v}^{\mathrm{TS}}=343,186$ and i119 $\mathrm{cm}^{-1}$ (only frequencies of $S$ atom were computed using the frozen mode approach where the relative displacement is equal to 0.01). We obtained $\nu_{2}^{*} \simeq 0.57 \mathrm{~T} \mathrm{~Hz}$.

We have also investigated $\Gamma_{1}$, which is the rotation rate of the solute-vacancy pair, using a NEB approach on a $3 \times 3 \times 3$ supercell. In this case, the transition state is also located in the middle of the path. We obtained $\mathrm{H}_{1}^{m}=0.70 \mathrm{eV}$, which is larger than $\mathrm{H}_{2}^{m}$. Thus, the quantity $f_{2} \Gamma_{2}$ can be approximated for sulfur in nickel by $\Gamma_{1}\left(\ll \Gamma_{2}\right)$.

Finally, we calculated the binding energy of the defect $(\mathrm{S}-\mathrm{V})$. We obtained approximately $0.36 \mathrm{eV}\left(=\mathrm{E}_{o}[(n-1) . \mathrm{Ni}]+\mathrm{E}_{o}[(n-\right.$ 1). $\left.\mathrm{Ni}+\mathrm{S}]-\mathrm{E}_{o}[(n-2) . \mathrm{Ni}+\mathrm{S}]-\mathrm{E}_{o}[n . \mathrm{Ni}]=\mathrm{G}^{B}\right)$, which suggests that $\mathrm{S}-\mathrm{V}$ is stable in comparison to the isolated defects ( $\mathrm{S}$ in substitution and a vacancy). The probability that a vacancy occupies a nearestneighboring site of the solute is not negligible, in particular at a low temperature.

Experimentally, there are two sets of data for the diffusivity: the first one is in "pure" nickel, where they obtain $\mathrm{Q}=2.0-2.28 \mathrm{eV}$ and $\mathrm{D}_{o}=0.2-0.4 \mathrm{~cm} \hat{A}^{2} / \mathrm{s}$ [15], and the second one is in nickel superalloys, which were measured by Smialek [6]: $\mathrm{Q}=1.63 \mathrm{eV}$ and $\mathrm{D}_{o}=$ $6.71 \cdot 10^{-3} \mathrm{~cm}^{2} / \mathrm{s}$. The activation energy, given by the sum of the formation energy of the vacancy (DFT value $+1.41 \mathrm{eV}[19,20]$ ), the migration energy $\mathrm{H}_{1}^{m}$ and the binding energy $\left(-\mathrm{G}^{B}\right)$, is equal to $\mathrm{Q}=\mathrm{H}_{1 v}^{m}+\mathrm{H}_{1}^{m}-\mathrm{G}^{B}=1.84 \mathrm{eV}$. Thus, the calculated value is slightly smaller than the experimental data (2.0/2.28 eV [15]).

The discrepancy between the experimental values and the calculated values of the activation energies for sulfur diffusion in pure nickel should be discussed. It can be noted that the lower value obtained by the DFT calculation could partly be explained by the low formation energy of the monovacancy, which was calculated using DFT (1.4 eV instead of the experimental value of $1.7 \mathrm{eV}$ ). This difference of $0.3 \mathrm{eV}$ is large enough to explain this discrepancy. If we compare the experimental activation energy of sulfur in pure nickel with those of other elements, we note that it is close to the value measured for $\mathrm{Nb}$, which is known to move slowly. It is interesting that, although the $S$ atoms move quickly, and its diffusivity is controlled by the rotation rate of the solute-vacancy pair. 
3.3. $S-S$ and $S-V$ interactions in a monovacancy site and a divacancy site

We have shown that the $\mathrm{S}$ atoms are located in substituted sites, and we are interested in the number of $\mathrm{S}$ atoms that can be placed in one and two nearest neighboring nickel sites.

\subsection{1. $S_{m}$ clusters}

To study the " $S_{m}$ " clusterization we considered different " $S_{m}$ " configurations, as illustrated in Fig. 5.

We define three quantities to analyze the stability and the interactions of S-S in a nickel site. The first quantity corresponds to the solubility energies $\left(\mathrm{E}^{\mathrm{sol}}\left[\mathrm{S}_{m}\right]\right)$, as defined in the previous section:

$E^{\mathrm{sol}}\left[\mathrm{S}_{m}\right]=\mathrm{E}_{o}\left[(n-1) \cdot \mathrm{Ni}+\mathrm{S}_{m}\right]-\frac{n-1}{n} \cdot \mathrm{E}_{o}[n \cdot \mathrm{Ni}]-\frac{m}{2} \cdot \mathrm{E}_{o}\left[\mathrm{~S}_{2}\right]$.

The energy, which is associated to the ability of an $\mathrm{S}_{m-1}$ defect to trap an additional $\mathrm{S}$ atom $\left(\mathrm{E}^{\text {trap }}\left[\mathrm{S}_{m}\right]\right)$, is given by

$\mathrm{E}^{\mathrm{trap}}\left[\mathrm{S}_{m}\right]=\mathrm{E}_{o}\left[(n-1) \cdot N i+\mathrm{S}_{m}\right]-\left(\mathrm{E}_{o}\left[(n-1) \cdot N i+\mathrm{S}_{m-1}\right]+\frac{1}{2} \mathrm{E}_{o}\left[\mathrm{~S}_{2}\right]\right)$

i.e.,

$\mathrm{S}_{m-1}+\frac{1}{2} \cdot \mathrm{S}_{2} \rightleftharpoons \mathrm{S}_{m} \quad \mathrm{E}^{\mathrm{trap}}\left[\mathrm{S}_{m}\right]$.

When $m=1$, the trapping energy corresponds to the trapping energy of one sulfur in a monovacancy.

Finally, we define the binding energy ( $E^{\text {bind }}\left[S_{m}\right]$ ):

$$
\begin{aligned}
\mathrm{E}^{\mathrm{bind}}\left[\mathrm{S}_{m}\right]= & \left(\mathrm{E}_{o}\left[(n-1) \cdot \mathrm{Ni}+\mathrm{S}_{m}\right]+\mathrm{E}_{o}[(n-1) \cdot \mathrm{Ni}]\right) \\
& -\left(\mathrm{E}_{o}\left[(n-1) \cdot \mathrm{Ni}+\mathrm{S}_{m-1}\right]+\mathrm{E}_{o}[(n-1) \cdot \mathrm{Ni}+\mathrm{S}]\right)
\end{aligned}
$$

which corresponds to the energy to place an $\mathrm{S}$ atom from a substituted site into a site that is already occupied by another sulfur atom; thus, we create a new vacancy. A positive energy implies that the new defect " $\mathrm{S}_{m}$ " is unlikely to be created from the " $\mathrm{S}_{m-1}$ " defects.

The energies of the configurations are shown in Table 2. From a thermodynamic viewpoint, our simulations show that only one $\mathrm{S}$ atom can be located in a nickel site. The results on the solubility energy per $\mathrm{S}$ atom $\left(\mathrm{E}^{\text {sol }}\left[\mathrm{S}_{m}\right] / m\right)$ also suggest that when two $\mathrm{S}$ atoms are in the same site, it should form a dumbbell defect, which is oriented to the square faces. The other configurations are clearly energetically unfavorable because the steric and the electrostatic effects increase quickly and destabilize the clusters. Similarly, the binding and trapping energies lead to the same conclusion: the process to trap an additional sulfur atom in an already occupied site is not efficient because $E^{\text {trap }}$ $\left[S_{m}\right]>0$ for $m \geq 2$. Thus, it is not possible to restore an $S_{2}$ molecule
Table 2

Solubility energies per $\mathrm{S}$ atom $\left(\mathrm{E}^{\text {sol }}\left[\mathrm{S}_{m}\right] / m\right.$, in eV/S atom), trapping energies ( $\mathrm{E}^{\text {trap }}\left[\mathrm{S}_{m}\right]$ in $\mathrm{eV}$ ), binding energies (see text, $\mathrm{E}^{\text {bind }}\left[\mathrm{S}_{m}\right]$, in $\mathrm{eV}$ ) and $\mathrm{S}-\mathrm{S}$ distances (in $\AA$ ) of the " $\mathrm{S}_{m}$ " clusters. $\mathrm{S}=$ square configuration, $\mathrm{T}=$ triangle configuration.

\begin{tabular}{lcccll}
\hline $\mathrm{m}$ & & $\mathrm{E}^{\text {sol }}\left[\mathrm{S}_{m}\right] / m$ & $\mathrm{E}^{\text {trap }}\left[\mathrm{S}_{m}\right]$ & $\mathrm{E}^{\text {bind }}\left[\mathrm{S}_{m}\right]$ & $\mathrm{d}(\mathrm{S}-\mathrm{S})$ \\
\hline 1 & & -0.25 & -1.61 & - & - \\
2 & $\mathrm{~S}$ & 0.12 & 0.50 & 2.11 & 2.23 \\
& $\mathrm{~T}$ & 0.94 & 2.13 & 3.74 & 2.07 \\
3 & $\mathrm{~T}$ & 0.78 & 2.11 & 3.72 & $2.81^{\mathrm{a}}$ \\
\hline
\end{tabular}

a All S-S distances are equal.

inside a vacancy. The S-S distances (2.23, 2.07 and $2.81 \AA$ ) are much larger than the distance in the $S_{2}$ molecule (Exp.: $1.88 \AA$ and DFT: $1.90 \AA$ ).

\subsection{2. $S_{m} V_{2}$ clusters $(m=2-4)$}

The ability of a divacancy to trap $S$ atoms was also investigated. The used conformations $\left(S_{2} V_{2}, S_{3} V_{2}\right.$ and $\left.S_{4} V_{2}\right)$ are shown in Fig. 6 .

As in the previous section, we define different relevant energetic quantities to study the $S_{m} V_{2}$ clusters, which depend on the point of view considered (absolute stability, vacancy or divacancies). As previously defined, $\mathrm{E}^{\mathrm{sol}}$ corresponds to the solubility energy:

$\mathrm{E}^{\mathrm{sol}}\left[\mathrm{S}_{m} \mathrm{~V}_{2}\right]=\mathrm{E}_{o}\left[(n-2) \cdot \mathrm{Ni}+\mathrm{S}_{m}\right]-\frac{n-2}{n} \mathrm{E}_{o}[n \cdot \mathrm{Ni}]-\frac{m}{2} \mathrm{E}_{o}\left[\mathrm{~S}_{2}\right]$

The insertion energy, which is the cost to insert $S_{m}$ atoms into a divacancy ( $E^{\text {insert }}=E^{\text {sol }}-E_{2 v}^{f}$, where $E_{2 v}^{f}$ is the formation energy of the divacancy, $2.72 \mathrm{eV}$ ) is defined as

$\mathrm{E}^{\text {insert }}\left[\mathrm{S}_{m} \mathrm{~V}_{2}\right]=\mathrm{E}_{o}\left[(n-2) \cdot \mathrm{Ni}+\mathrm{S}_{m}\right]-\mathrm{E}_{o}[(n-2) \cdot \mathrm{Ni}]-\frac{m}{2} \mathrm{E}_{o}\left[\mathrm{~S}_{2}\right]$

$\mathrm{V}_{2}+\frac{m}{2} \mathrm{~S}_{2} \rightleftharpoons \mathrm{S}_{m} \mathrm{~V}_{2} \quad \mathrm{E}^{\text {insert }}\left[\mathrm{S}_{m} \mathrm{~V}_{2}\right]$

A negative insertion energy implies that the insertion of " $\mathrm{S}_{m}$ " defects inside a divacancy is a favorable thermodynamic process. The binding energy ( $E^{\text {bind }}$ ) is given by

$$
\begin{aligned}
\mathrm{E}^{\mathrm{bind}}\left[\mathrm{S}_{m} \mathrm{~V}_{2}\right]= & \left(\mathrm{E}_{o}\left[(n-2) \cdot \mathrm{Ni}+\mathrm{S}_{m}\right]+\mathrm{E}_{o}[(n-1) \cdot \mathrm{Ni}]\right) \\
& -\left(\mathrm{E}_{o}\left[(n-2) \cdot \mathrm{Ni}+\mathrm{S}_{m-1}\right]+\mathrm{E}_{o}[(n-1) \cdot \mathrm{Ni}+\mathrm{S}]\right)
\end{aligned}
$$

The simulation results are shown in Table 3.

The " $S_{1} V_{2}$ " defect $\left(E^{\text {sol }}>0\right)$ is less thermodynamically favorable than the others configurations. However, the insertion and binding energies suggest that the $S$ atoms are attracted by the divacancies to build clusters. Likewise, the interaction between an $\mathrm{S}$ atom and a vacancy in the first neighboring position is attractive $(0.36 \mathrm{eV}$, see the discussion on the migration of $\mathrm{S}$ atoms).
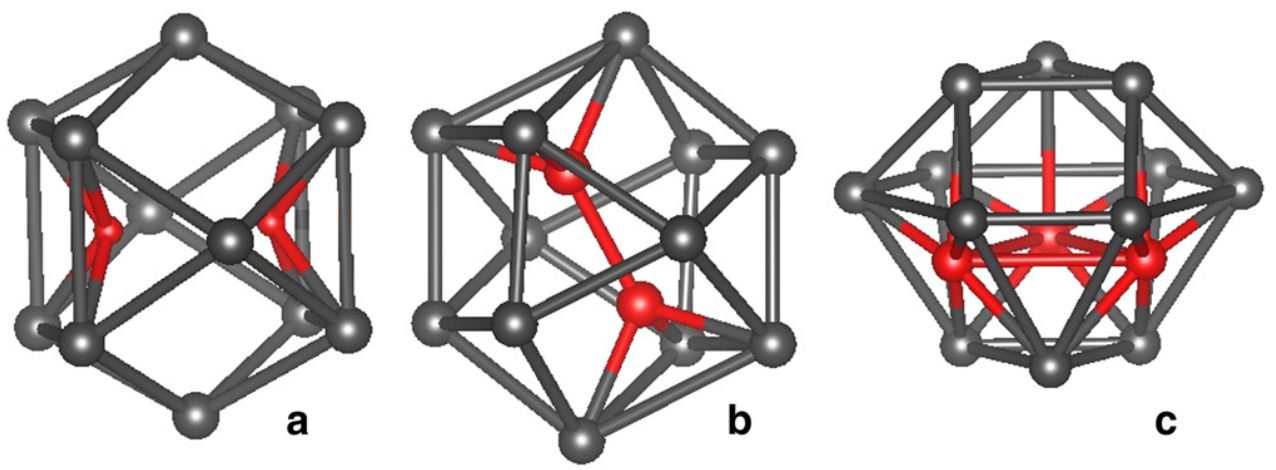

Fig. 5. " $\mathrm{S}_{m}$ " configurations considered (in gray nickel and in red sulfur): (c) $\mathrm{m}=2 \mathrm{~S}$ atoms in one nickel site (S atoms are observed through the square faces of the volume) (left), (b) $\mathrm{m}=2 \mathrm{~S}$ atoms are placed along the triangle face (center), and (a) $\mathrm{m}=3 \mathrm{~S}$ atoms are placed along the square faces (right). 


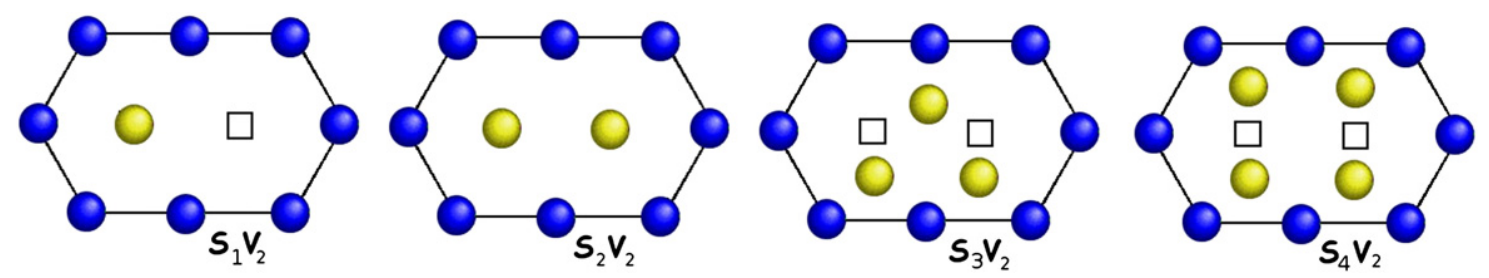

Fig. 6. Representation of the $S_{m} V_{2}$ defects.

The second configuration that we studied $\left(\mathrm{V}_{2} \mathrm{~S}_{2}\right)$ consists of two $\mathrm{S}$ atoms in the $1 \mathrm{NN}$ position. Its positive formation energy implies that it is a stable cluster, which can be explained by an attractive (negative) interaction between the two atoms $\left(\mathrm{E}_{o}\left[(n-2) \cdot \mathrm{Ni}+\mathrm{S}_{2}\right]+\mathrm{E}_{o}\right.$ $\left.[(n-1) . \mathrm{Ni}]-2 \mathrm{E}_{o}[(n-1) . \mathrm{Ni}+\mathrm{S}]=-0.49 \mathrm{eV}\right)$. The binding and insertion energies reflect the same trend: the $S_{2} V_{2}$ defects are stable, and the trapping of an additional $S$ atom by an $S^{1} V$ cluster is energetically favored. When two $S$ atoms are trapped in the divacancy, each of them should be located in place of the two Ni missing atoms, but the electrostatic S-S repulsion increases their distance from 2.49 to $3.03 \AA$; hence, although the electron transfer from the nickel atoms to the sulfur atom remains of the same order, the $\mathrm{S}-\mathrm{S}$ repulsion energy is much smaller than that in a monovacancy, which increases the trapping energy of the second $\mathrm{S}$ atom.

When three and four S atoms are absorbed in the divacancy, the electrostatic repulsion increases significantly because of the steric effects. Then, the binding energy from the three $S$ atoms becomes negative. For three absorbed $\mathrm{S}$ atoms, two of them are located in one of the vacancies (similar to the monovacancy scheme), and the third one is located near the other vacancy. The $E^{\text {insert }}\left[S_{m} V_{2}\right]$ value indicates that it is always thermodynamically stable to insert $S_{m}$ atoms into $\mathrm{V}$.

\section{Surface results}

\subsection{Optimization of the $\mathrm{Ni}(100)$ and $\mathrm{Ni}(111)$ surfaces}

Now, we are interested in the adsorption and segregation energies on the dense surfaces, which are the $\mathrm{Ni}(100)$ and $\mathrm{Ni}(111)$ surfaces. To validate our surfaces, we computed their surface energies $\left(\gamma_{\text {surf }}\right)$ using:

$\gamma_{\text {surf }}=\frac{1}{2}\left(\mathrm{E}_{\text {slab }}-l \cdot \mathrm{E}_{\text {layer }}\right)$

where $\mathrm{E}_{\text {slab }}$ is the total energy of the slab, $\mathrm{E}_{\text {layer }}$ is the total energy of the layer in the bulk crystal, and $l$ is the number of atomic layers. As remarked by Boettger [25], to obtain a well converged surface energy for a varying thickness slab, it is crucial to ensure that $\mathrm{E}_{\text {layer }}$ is consistent with the large $l$ limit of the incremental energy difference

Table 3

Energies (in $\mathrm{eV}$ ) of the $\mathrm{S}_{\mathrm{m}} \mathrm{V}_{2}$ defects (see text) according to the number of $\mathrm{S}$ atoms in the cluster.

\begin{tabular}{lcll}
\hline $\mathrm{m}$ & $\mathrm{E}^{\text {sol }}\left[\mathrm{S}_{m} \mathrm{~V}_{2}\right]$ & $\mathrm{E}^{\text {insert }}\left[\mathrm{S}_{m} \mathrm{~V}_{2}\right]$ & $\mathrm{E}^{\text {bind }}\left[\mathrm{S}_{m} \mathrm{~V}_{2}\right]$ \\
\hline 0 & $2.72^{\mathrm{a}}$ & - & - \\
1 & 0.75 & -1.98 & -0.36 \\
2 & -1.00 & -3.72 & -0.13 \\
3 & -0.47 & -3.20 & 2.14 \\
4 & 0.97 & -1.76 & 3.05 \\
\hline
\end{tabular}

${ }^{\text {a }}$ It corresponds to the formation energy of the divacancy. of the slab. $\mathrm{E}_{\text {layer }}$ can be accurately determined from the linear plot of $E_{\text {slab }}$ vs $l$, as a linear regression. The intersection of this plot with the Y-axis provides the value of double-surface energy. In Table 4, we list the experimental and theoretical values of these surface energies.

Our results for both surfaces agree with the results in previous theoretical and experimental works.

\subsection{Adsorption of sulfur on the $\mathrm{Ni}(100)$ and $\mathrm{Ni}(111)$ surfaces}

First, we determined the adsorption energy of the $S$ atom on the $\mathrm{Ni}(100)$ and $\mathrm{Ni}(111)$ surfaces. The adsorption energies $\mathrm{E}_{h k l}^{a d}[\mathrm{~S}]$ are referenced to the isolated $S$ atom energy $\left(\mathrm{E}_{o}\left[\mathrm{~S}_{\text {atom }}\right]\right)$ :

$\mathrm{E}_{h k l}^{a d}[\mathrm{~S}]=\mathrm{E}_{o}[\operatorname{surf}](\mathrm{hkl})+\mathrm{E}_{o}\left[\mathrm{~S}_{\text {atom }}\right]-\mathrm{E}_{\mathrm{o}}\left[\operatorname{surf}+\mathrm{S}^{a d}\right](\mathrm{hkl})$

where $E_{o}\left[\right.$ surf $\left.+S^{a d}\right](h k l)$ is the energy of the slab and of an $S$ atom for different adsorption sites of the Ni(hkl) surface. Various adsorption sites were considered (linear, bridge, 4-order and three-hollow sites) as illustrated in Fig. 7.

Our results and the data from the literature are listed in Table 5.

The 4-order site is the most stable site on the Ni(100) surface, whereas the three-hollow site is the most stable site on the $\mathrm{Ni}(111)$ surface. For each of them, we list in Table 5 the adsorption energies $\mathrm{E}^{a d}[\mathrm{~S}]$, the S-surface distance $d_{\perp}$ and the nickel-sulfur stretching frequency. Regarding the $\mathrm{Ni}(100)$ surface properties, our results agree with the other experimental and theoretical works. However, the comparison is less easy for the $\mathrm{Ni}(111)$ surface because the previous experimental and theoretical results vary. Nevertheless, our results show adequate agreement with those of Wang and Liu [31] for $\mathrm{E}_{a d}$ and $d_{\perp}$, Choi et al. [32] for $d_{\perp}$, and Black [33] for $\varpi_{\perp}$.

\subsection{Segregation of $S$ to the surfaces}

We conclude with the segregation of S atom into the surface. The segregation energy is defined as the difference in energy between two configurations: $\mathrm{S}$ atom in the bulk $\left(\mathrm{E}_{o}^{\mathrm{vol}}\left[\mathrm{S}_{\mathrm{sub}}\right]\right)$ and $\mathrm{S}$ atom in the first atomic layer of the surface $\left(\mathrm{E}_{o}^{\text {surf }}[\mathrm{S}]\right)$ :

$$
\mathrm{E}^{\mathrm{seg}}[\mathrm{S}]=\mathrm{E}_{o}^{\mathrm{vol}}\left[\mathrm{S}_{\mathrm{sub}}\right]-\mathrm{E}_{o}^{\text {surf }}[\mathrm{S}]
$$

Table 4

Surface energies of the $\mathrm{Ni}(100)\left(\gamma_{100}\right)$ and $\mathrm{Ni}(111)\left(\gamma_{111}\right)$ surfaces. All values are measured in $\mathrm{J} / \mathrm{m} \hat{A}^{2}$.

\begin{tabular}{lll}
\hline & $\gamma_{100}$ & $\gamma_{111}$ \\
\hline This work & 2.16 & 1.88 \\
Theo. & $1.98^{1} / 2.42^{2} / 1.76^{3}$ & $1.86^{1} / 2.01^{2} / 1.62^{3}$ \\
Exp. & $2.38^{4} / 2.45^{5}$ &
\end{tabular}

${ }^{1}$ MEDF method [26]; ${ }^{2}$ FCD-GGA method [27]; ${ }^{3}$ EAM [28]; ${ }^{4}$ EAM [29]; ${ }^{5}$ for polycrystalline surfaces [30]. 

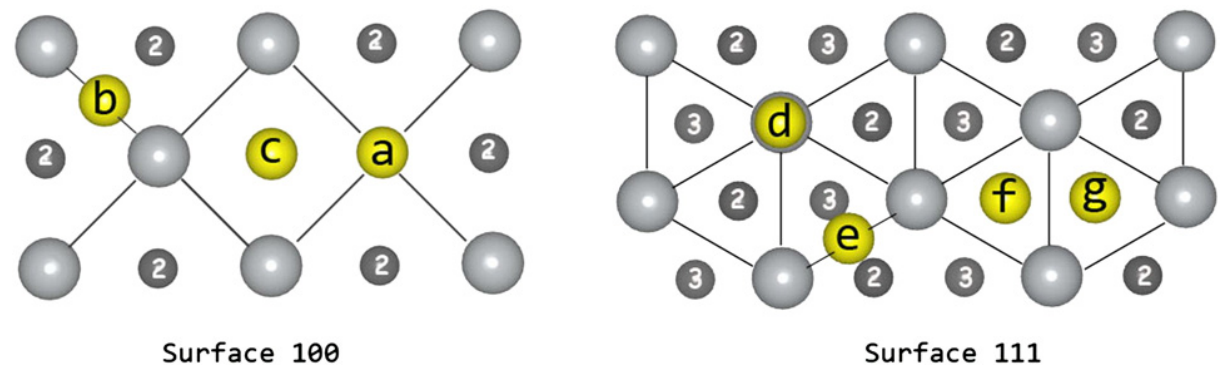

Fig. 7. Representation of different adsorption sites that were considered.

Table 5

Adsorption energies of $\mathrm{S}\left(\mathrm{E}_{\mathrm{hkl}}^{a d}[\mathrm{~S}]\right.$, measured in $\mathrm{eV}$ ) on various sites on the $\mathrm{Ni}(100)$ and $\mathrm{Ni}(111)$ surfaces, the sulfur-surface perpendicular distance (in $\AA$ ) and the stretching frequencies $\left(\varpi_{\perp}\right.$, measured in $\left.\mathrm{cm}^{-1}\right)$.

\begin{tabular}{lllll}
\hline$(\mathrm{hkl})$ & Site & $\mathrm{E}_{\mathrm{hkl}}^{\text {ad }}[\mathrm{S}]$ & $d_{\perp}$ & $\varpi_{\perp}$ \\
\hline$(100)$ & 4-order & 6.09 & 1.30 & 337 \\
& Linear & 3.94 & 2.00 & \\
Other (100) & Bridge & 4.95 & 1.60 & \\
& & $5.97^{1}$ & $1.32^{1}$, & $351^{3}$ \\
$(111)$ & & & $1.30 \pm 0.01^{2}$ & \\
& 3-order & 5.38 & 1.54 & 494 \\
& Linear & 3.91 & 2.01 & \\
Other (111) & Bridge & 5.13 & 1.56 & \\
& & $5.29^{1}, 5.44^{4}$, & $1.54^{1}, 1.55^{4}$, & $441^{4}, 471^{6}$, \\
& & $3.77^{5}$ & $1.59^{7}$ & $399^{7}$ \\
\hline
\end{tabular}

${ }^{1}$ Ref. [31], ${ }^{2}$ Ref. [34], ${ }^{3}$ Ref. [35], ${ }^{4}$ Ref. [32], ${ }^{5}$ Ref. [36], ${ }^{6}$ Ref. [33], ${ }^{7}$ Ref. [37].

This energy finding illustrates the loss (or the gain) in energy when the sulfur atom moves from the bulk towards the surface. This quantity is independent of the reference sulfur atom or molecule.

For an atom on the surface (in the first atomic layer of the surface), its solubility energy was calculated using an equation that is equivalent to Eq. (4). We obtained approximately $1.86 \mathrm{eV}$ for $\mathrm{Ni}(100)$ and $1.57 \mathrm{eV}$ for $\mathrm{Ni}(111)$. Therefore, the atom has a much smaller solubility energy on the surfaces than in the volume $(0.25 \mathrm{eV})$. We also computed the solubility of the $\mathrm{S}$ atom in the slab with the same system (box). We obtain $0.21 \mathrm{eV}$ and $0.13 \mathrm{eV}$ for the $\mathrm{Ni}(100)$ and $\mathrm{Ni}(111)$ slabs, respectively, instead of $0.25 \mathrm{eV}$, which was previously calculated. The differences could be associated to the unrelaxed cell and the size (along $z$ axis) of the slab. The accuracy is approximately $0.1 \mathrm{eV}$.

In the end, we obtain a segregation energy of $1.65 / 1.60 \mathrm{eV}$ for the $\mathrm{Ni}(100)$ surface and $1.45 / 1.34 \mathrm{eV}$ for the $\mathrm{Ni}(111)$ surface, which were calculated using either the slab energies $(0.21$ and $0.13 \mathrm{eV})$ or the energy of the solubility volume (i.e., $+0.25 \mathrm{eV}$ ). Our results are in excellent agreement with the experimental values of Miyahara [8], who obtained a segregation energy of $1.4 \mathrm{eV}$ for the $\mathrm{Ni}(100)$ surface, and of McCarty, who obtained $2.0 \mathrm{eV}$ for the same type of surface.

\section{Conclusions}

To summarize, we investigated several sulfur absorption processes in bulk nickel and the chemisorption on the $\mathrm{Ni}(100)$ and $\mathrm{Ni}(111)$ surfaces. Several new data are presented in this work regarding the $\mathrm{S}$ atom in nickel. The first-principle calculations prove that sulfur absorption occurs in the substitutional site, and we determine the solubility and migration energies of $\mathrm{S}$ atom in solid solution. Furthermore, this study shows that only one sulfur atom may be located in a site because of a strong electrostatic repulsion between $\mathrm{S}$ atoms.
In addition, the adsorption on $\mathrm{Ni}(100)$ and $\mathrm{Ni}(111)$ surfaces occupy the most coordinated sites. Finally, the calculated ab initio segregation energies of $\mathrm{S}$ atoms on various surfaces are in good agreement with the experimental data.

\section{Acknowledgments}

This work was granted access to the HPC resources of CALMIP (CICT Toulouse, France) under the allocations 2011/2012-p0850 and 2012-p0842.

\section{References}

[1] N. Barbouth, J. Oudar, Mém. Etudes Sc Rev. Métall. 12 (1989) 777.

[2] R. Molins, P.Y. Hou, Surf. Coat. Technol. 201 (2006) 3841.

[3] R. Brill, S. Tauster, Ber. Bunsenges. Phys. Chem. 67 (1963) 390.

[4] A.W. Funkenbusch, J.G. Smeggil, N.S. Bornstein, Metall. Mater. Trans. A 16 (1985) 1164.

[5] T. Gheno, D. Monceau, D. Oquab, Y. Cadoret, Oxid. Met. 73 (2010) 95.

[6] J.L. Smialek, Metall. Trans. A 18 (1987) 164.

[7] N. Vialas, D. Monceau, Surf. Coat. Technol. 201 (2006) 3846.

[8] T. Miyahara, K. Stolt, D.A. Reed, H.K. Birnbaum, Scr. Metall. 19 (1985) 117.

[9] G. Kresse, J. Hafner, Phys. Rev. B 47 (1993) 558, (49 (1994) 14251); G. Kresse, J. Furthmüller, Phys. Rev. B 54 (1996) 11169; G. Kresse, J. Furthmüller, Comput. Mater. Sci. 6 (1996) 15.

[10] G. Kresse, D. Joubert, Phys. Rev. B 59 (1999) 1758.

[11] Y. Wang, J.P. Perdew, Phys. Rev. B 44 (1991) 13298.

[12] H.J. Monkhorst, J.D. Pack, Phys. Rev. B 13 (1976) 5188.

[13] B. Meyer, Chem. Rev. 269 (1976) 1618.

[14] B. Eckert, R. Steudel, Top. Curr. Chem. 231 (2003) 181.

[15] N. Barbouth, J. Oudar, C. R. Acad. Sci. 269 (1969) 1618.

[16] E.H. Megchiche, M. Amarouche, C. Mijoule, J. Phys. Condens. Matter 19 (2007) 296201.

[17] A.B. Lidiard, Philos. Mag. 46 (1955) 1218; ibid 5 (1960) 1171.

[18] Y. Adda, J. Philibert, La Diffusion dans les solides, Bibliothèque des sciences et techniques nucléaires, Presse Universitaire de France PUF, 1965.

[19] D. Connétable, B. Ter-Ovanessian, E. Andrieu, J. Phys. Condens. Matter 24 (2012) 095010.

[20] E.H. Megchiche, S. Pérusin, J.-C. Barthelat, C. Mijoule, Phys. Rev. B 74 (2006) 064111.

[21] J. Manning, Phys. Rev. 136 (1964) A1758.

[22] G.H. Vineyard, J. Phys. Chem. Solids 3 (1957) 121.

[23] D. Connétable, B. Max, E. Andrieu and B. Viguier (to be published).

[24] P. Marcus, J. Oudar, Mater. Sci. Eng. 42 (1980) 191

[25] J.C. Boettger, Phys. Rev. B 53 (1996) 13133.

[26] V.M. Kuznetsov, R.I. Kadyrov, G.E. Rudenskii, J. Mater. Sci. Technol. 14 (1998) 320.

[27] L. Vitos, A.V. Ruban, H.L. Skriver, J. Kollár, Surf. Sci. 411 (1998) 186.

[28] S.P. Chen, D. Srolovitz, A.F. Voter, J. Mater. Res. 4 (1989) 62.

[29] W.R. Tyson, W.A. Miller, Surf. Sci. 62 (1977) 267.

[30] F.R. de Boer, R. Boom, W.C.M. Mattens, A.R. Miedema, A.K. Niessen, Cohesion in Metals, North-Holland, Amsterdam, 1988.

[31] J.-H. Wang, M. Liu, Electrochem. Com. 9 (2007) 2212.

[32] Y.M. Choi, C. Compson, M.C. Lin, M. Liu, J. Alloy Comp. 427 (2007) 25.

[33] J.E. Black, Surf. Sci. 105 (1981) 59.

[34] D.R. Mullins, T. Tang, X. Chen, V. Shneerson, D.K. Saldin, W.T. Tysoe, Surf. Sci. 372 (1997) 193.

[35] S. Andersson, P.A. Karlsson, M. Perrson, Phys. Rev. Lett. 51 (1983) 2378.

[36] H. Yang, J.L. Whitten, Surf. Sci. 370 (1997) 136.

[37] M.A. Chesters, D. Lennon, L. Ackermann, O. Häberlen, S. Krüger, N. Rösch, Surf. Sci. 291 (1993) 177. 